\title{
COMO TORNAR OS TERMOS DE CONSENTIMENTO MAIS FÁCEIS DE LER?
}

\author{
Diego Vinicius Pacheco de Araujo ${ }^{1}$, Elma lourdes Campos Pavone Zoboli ${ }^{\star \star}$, Eduardo Massad
}

Trabalho realizado na Escola de Enfermagem da Universidade de São Paulo, São Paulo, SP

*Correspondência:

Escola de enfermagem da Universidade de São Paulo Av. Dr. Enéas de Carvalho Aguiar, 419

São Paulo - SP

CEP: 05403-000

elma@usp.br

\section{RESUMO}

OвjEtivo. Reconhecer o nível de alfabetismo funcional de usuários do ambulatório do Hospital das Clínicas da Faculdade de Medicina da Universidade de São Paulo (HCMFUSP) com a finalidade de identificar recomendações para adequar a redação do TCLE ao nível de alfabetismo dos usuários, pois estes podem vir a ser sujeitos de pesquisa.

MÉtodos. Estudo transversal quantitativo com 399 sujeitos. A amostra foi intencional, selecionada entre usuários dos ambulatórios do HCFMUSP. A coleta de dados utilizou instrumento que continha um texto em prosa compatível para a avaliação das habilidades de leitura necessárias para a compreensão de um TCLE.

Resultados. Mais de 46,6\% dos entrevistados foram classificados como analfabetos funcionais. Desses, $12,7 \%$ sequer foram capazes de entender a tarefa proposta no texto lido. Apesar disto, quase $50 \%$ dos entrevistados declararam ter ao menos iniciado o ensino médio.

Conclusã̃o. Os resultados e as orientações para a redação de texto centrada no leitor permitiu que elaborássemos recomendações para tornar os termos de consentimento mais fáceis de ler. Recomendamos que o pesquisador elabore o TCLE como um texto em estrutura narrativa, dirigido ao leitor, usando palavras e termos familiares, ou seja, termos comuns à linguagem dos sujeitos e à linguagem médica. Além de contribuir para melhorar a relação entre o sujeito e o pesquisador, acredita-se que estas recomendações possam contribuir para a diminuição do tempo de tramitação de projetos de pesquisa. Já que os problemas na redação do TCLE motivam boa parte das pendências que retardam este andamento.

Unitermos: Comitês de Ética em Pesquisa. Bioética. Termos de consentimento. Escolaridade.

\section{INTRODUÇÃO}

O consentimento livre e esclarecido é um elemento crucial na assistência e pesquisa em saúde. Entretanto, existem inúmeras barreiras de comunicação e compreensão entre sujeitos e pesquisadores que podem dificultá-lo. Entre elas, o nível de educação dos sujeitos e a compreensão da linguagem escrita do Termo de Consentimento Livre e Esclarecido (TCLE) nos protocolos de pesquisa são frequentemente mencionados e estudados.

Uma das funções dos Comitês de Ética em Pesquisa é avaliar a clareza do vocabulário empregado no TCLE sendo verificados os termos e expressões utilizados, de acordo com a linguagem dos sujeitos da pesquisa. A falta de clareza do TCLE é o motivo da maior parte das pendências de protocolos ${ }^{1}$.

Os pacientes, e por conseguinte os sujeitos de pesquisa, têm expectativas e desejam informações sobre sua saúde em linguagem compreensível.

A linguagem apropriada para o TCLE é aquela familiar aos sujeitos de pesquisa, ou seja, uma linguagem fácil de entender, que utiliza palavras comuns e aproxima o texto à realidade da pessoa. O nível de alfabetização do sujeito é um elemento essencial desta realidade e que, obviamente, diz respeito diretamente à linguagem a ser usada na redação do TCLE.

No Indicador Nacional de Alfabetismo Funcional (Inaf) considera-se analfabetismo a condição dos que não conseguem realizar tarefas simples que envolvem a leitura de palavras e frases. O alfabetismo rudimentar corresponde à capacidade de localizar uma informação explícita em textos curtos e familiares. O alfabetismo nível básico inclui as pessoas que lêem, compreendem textos de média extensão e localizam informações necessárias para realizar pequenas inferências, porém mostram limitações para fazer isto em textos mais extensos ou que envolvam maior número de relações entre as informações. No alfabetismo nível pleno estão as pessoas cujas habilidades não impõem restrições para compreender e interpretar elementos usuais da sociedade letrada ${ }^{2,3}$.

Sinteticamente os quatro níveis de alfabetismo descritos pelo Inaf podem ser agrupados em: analfabetos funcionais (analfabetos absolutos e analfabetizados em nível rudimentar) e funcionalmente alfabetizados (níveis básico e pleno de alfabetização)².

1. Graduação em enfermagem - Bolsista CAPES / Mestrado pela Universidade de São Paulo - USP, São Paulo, SP

2. Pós-doutorado - docente da Universidade de São Paulo - USP, São Paulo, SP

3. Livre-docência - professor titular da Universidade de São Paulo - USP, São Paulo, SP 
No Brasil, entre 2001 e 2007, o grupo dos analfabetos funcionais passou de $39 \%$ para $32 \%$ da população e os alfabetizados funcionais cresceram de $61 \%$ para $68 \%{ }^{4}$.

Entre as pessoas de 14 a 64 anos só $47 \%$ completaram a $8^{a}$ série do ensino fundamental. Ou seja, 53\% não têm o nível escolar que a Constituição Federal Brasileira afirma ser o direito mínimo de todo cidadão ${ }^{3}$. Sem o Ensino Fundamental completo é difícil garantir o nível básico de alfabetização, pois este nível só é majoritário (57\%) na população com, no mínimo, Ensino Médio, isto é, entre os que tem 11 anos ou mais de estudo ${ }^{3}$.

A região Sul possui o mais alto nível de alfabetismo, com $71 \%$ da população pertencente ao grupo dos funcionalmente alfabetizados. Desses, 1/3 são plenamente alfabetizados, esta situação é semelhante a da região Sudeste onde $67 \%$ da população é funcionalmente alfabetizada, sendo $28 \%$ plenamente alfabetizados. Porém, a região Nordeste possui $46 \%$ da população caracterizada como analfabetos funcionais. A ocorrência de analfabetismo funcional é associada a condições socioeconômicas desfavoráveis e a grupos raciais e étnicos historicamente em situação de discriminação. É fato que o grau de escolaridade varia proporcionalmente à melhoria das condições socioeconômicas das populações².

Mesmo nos casos em que usuários do Sistema Único de Saúde (SUS) se declarem alfabetizados e sejam capazes de assinar seu nome no TCLE, eles possuem grande chance de serem analfabetos funcionais, o que poderia comprometer a compreensão das informações contidas no TCLE.

O objetivo deste estudo foi reconhecer o nível de alfabetismo funcional de usuários do ambulatório do Hospital das Clínicas da Faculdade de Medicina da Universidade de São Paulo (HCMFUSP) com a finalidade de identificar recomendações para adequar a redação do TCLE utilizado nas pesquisas do HCFMUSP ao nível de alfabetismo de seus usuários, pois estes podem vir a ser sujeitos de pesquisa.

As recomendações propostas para tornar a redação do TCLE mais clara têm o propósito de contribuir para um processo de consentimento mais efetivo.

\section{Métodos}

Trata-se de um estudo transversal quantitativo realizado no Prédio dos Ambulatórios (PAMB) do HCFMUSP.

Foram incluídos 399 sujeitos em uma amostra intencional. A amostra foi calculada com base nos dados de $33 \%$ de analfabetismo funcional na região Sudeste ${ }^{4}$ e a confiabilidade foi de 95\% ${ }^{5}$, sendo que o mínimo previsto era 340 sujeitos.

Os sujeitos de pesquisa foram recrutados entre os usuários do PAMB convidados a participar do estudo enquanto aguardavam atendimento.

Os critérios de inclusão foram: declarar-se alfabetizado, independente de ter frequentado o sistema formal de educação; ser maior de 18 anos e menor de 65 anos; ser usuário do HCFMUSP; ter consentido em participar da pesquisa; ter como língua de alfabetização primária o português do Brasil; não estar em atendimento no ambulatório de geriatria; não estar em atendimento no ambulatório de endocrinologia.

Os critérios de exclusão foram: declarar-se analfabeto; ser menor de 18 anos ou maior de 65 anos; estar em tratamento na psiquiatria; ter dificuldade física que impedisse a leitura; ser portador de doença metabólica que impedisse a cognição; ter como língua de alfabetização primária outra que não o português do Brasil; estar em atendimento no ambulatório de geriatria; estar em atendimento no ambulatório de endocrinologia.

O instrumento para coleta de dados foi o mesmo utilizado em estudo similar desenvolvido no Hospital de Clínicas de Porto Alegre ${ }^{6}$. O texto adotado como instrumento de coleta de dados foi um dos utilizados na participação brasileira em uma pesquisa sobre o analfabetismo funcional na América Latina, realizada no início da década de 90 pela Oficina Regional de Educación para America Latina y Caribe (OREALC), órgão da Organização das Nações Unidas para a Educação, a Ciência e a Cultura (UNESCO) ${ }^{4}$.

Centramos o estudo na alfabetização para leitura de textos em prosa por sua semelhança com o TCLE, enquanto texto informativo. A avaliação do alfabetismo funcional pode ser realizada, de maneira ampla, por meio das habilidades de alfabetização usando textos em prosa, textos esquemáticos e textos com informação numérica. A alfabetização em textos em prosa envolve o conhecimento e as habilidades necessárias para compreender e utilizar informação tanto de textos expositivos quanto narrativos, como editoriais, matérias de revistas, jornais, poemas, ficção, entre outros ${ }^{7}$.

Os textos em prosa, têm diferentes graus de dificuldade. Considerando as habilidades que o leitor do TCLE deve dominar, o instrumento de coleta de dados usado no presente estudo continha um texto do nível 4. Neste nível, os participantes devem localizar ou processar mais de uma informação em textos mais especializados, estabelecendo relações de causa e efeito ${ }^{7}$.

O texto em prosa era seguido de uma tarefa proposta sob a forma de pergunta. O pressuposto é que existe um conjunto de habilidades de alfabetização necessário para se cumprir diferentes tipos de tarefas ${ }^{7}$.

O texto discorria sobre o atual estado de desmatamento das florestras tropicais e a pergunta realizada após a sua leitura era: 'Quais as consequências das florestas tropicais estarem acabando?' E, com base nas informações do texto as duas respostas esperadas eram: 'extinção de animais e plantas' e 'aumento do volume de água nos rios'.

O desempenho do sujeito na leitura do texto foi avaliado de acordo com o número de consequências citadas pelo entrevistado nas respostas. Quem 'não citou consequências' ou 'não compreendeu a proposta' foi classificado como 'nível rudimentar de alfabetização', por se considerar que não foi capaz de indicar nenhuma das duas informações relevantes no texto. 0 sujeito que 'citou uma consequência' foi classificado como 'nível básico de alfabetização', por ser capaz de selecionar apenas uma das duas informações relevantes do texto. Por fim, quem 'citou duas consequências' foi classificado como 'nível pleno de alfabetização', ou seja, compreendeu o texto e estabeleceu relações e inferências para poder identificar as duas consequências, já que apenas uma delas estava explicitamente colocada.

Assim, o nível de alfabetismo do entrevistado foi classificado com base nas habilidades requeridas para a tarefa de localização nos textos em prosa, na qual os leitores devem ser capazes de referir a informação dada na questão em forma literal, ou seja, da mesma maneira com que estava escrita no texto. Também foram avaliadas as habilidades para a tarefa de integração na 
qual os leitores deveriam ser capazes de juntar duas ou mais peças de informação localizadas em partes diferentes do texto.

Foram coletadas informações demográficas, como idade, sexo, cor, escolaridade em nível escolar - ensino fundamental $(E F)$, ensino médio (EM), ensino superior (ES) - escolaridade em anos de estudo; última série cursada pelo sujeito; profissão; procedência e tempo de residência em São Paulo.

O projeto de pesquisa foi aprovado pela Comissão de Ética para Análise de Projetos de Pesquisa do Hospital das Clínicas da Faculdade de Medicina da Universidade de São Paulo.

Os dados foram analisados por meio do SPSS versão 17.0 (SPSS Inc.,EUA), e a significância estatística foi avaliada pelo teste Qui quadrado de Pearson. O nível de significância estabelecido foi de $5 \%(p<0,05)$.

\section{Resultados}

Os sujeitos da pesquisa foram representados por 178 homens $(44,6 \%)$ e 221 mulheres (55,4\%). A idade média foi 38,25 anos com um desvio padrão de $\pm 11,62$ e os limites inferior e superior foram 18 e 65 anos, respectivamente.

Do total de entrevistados, 379 pessoas moravam no Estado de São Paulo, 18 moravam em outros Estados do Brasil e duas pessoas não responderam essa questão. Esta distribuição é compatível com o perfil de atendimento do HCFMUSP.

Dos residentes em São Paulo, $269(67,4 \%)$ eram natos do Estado. Dos migrantes, a média de residência em São Paulo era 22,6 anos, com um valor máximo de 57 anos e mínimo um ano.

A média de anos de estudo foi $10 \pm 3,6$. Um dos sujeitos nunca frequentou a escola, apesar de declarar-se em condições de realizar a leitura, e outro tinha 29 anos de estudo.

Quanto à região de nascimento, três pessoas nasceram na Centro-Oeste, três na Norte, 14 na Sul, 83 na Nordeste e 296 pessoas nasceram na Sudeste, ou seja, $74,1 \%$ das pessoas entrevistadas nasceram na região Sudeste e 20,8\% procediam do Nordeste.

O agrupamento da variável nível de escolaridade não levou em conta a conclusão do nível citado pelo entrevistado. Assim, as pessoas que estudaram apenas o primeiro ano do EM estão no mesmo grupo daquelas que o concluíram. A maioria (199 pessoas - 49,9\%) declarou ter estudado o equivalente ao EM, sendo que destes, 163 pessoas haviam estudado até o $3^{\circ}$ ano do EM. Oitenta (80) pessoas 20,1\% estavam cursando ou já haviam cursado o ES, sendo que destas, nove (2,3\% do total) estavam cursando ou já haviam concluído algum curso de pósgraduação (mestrado ou doutorado).

Cento e dezoito (118) entrevistados 29,6\% declararam ter o Ensino Fundamental, sendo que apenas 48 pessoas o haviam completado, cursando até a $8^{\mathrm{a}}$ série.

Quanto à compreensão de leitura, 185 pessoas não responderam nenhuma das alternativas ao serem questionadas sobre as consequências do desmatamento: 51 'não compreendeu a proposta' e, 135 'não citou consequências'. Das 139 pessoas classificadas no 'citou uma consequência' 109 responderam a alternativa referente à extinção de animais e plantas e 30 pessoas responderam a alternativa referente ao aumento do volume de água dos rios.

Apenas 74 pessoas, ou seja, 18,5\% da amostra foi classificada no 'citou duas consequências'
As pessoas que 'não compreenderam a proposta', geralmente, respondiam causas e não consequências, indicando que não haviam compreendido o texto e, tampouco, a pergunta feita pelo entrevistador. Ou seja, não demonstraram habilidades de letramento para entender a tarefa proposta e localizar as informações no texto.

Considerando a Classificação de Alfabetismo Funcional, 186 (46,61\%) sujeitos estavam no nível rudimentar de alfabetização, sendo considerados analfabetos funcionais. No nível básico de alfabetização, encontrou-se 139 (34,84\%) sujeitos e no nível pleno 74 (18,55\%) que, somados, formam o grupo dos funcionalmente alfabetizados. Vale lembrar que todos esses sujeitos declararam-se alfabetizados antes de participarem do estudo, já que este era um dos critérios de inclusão.

O intervalo com $95 \%$ de confiança para a proporção de analfabetos funcionais é $[41,7 \%-51,5 \%]$ e de alfabetizados funcionalmente é de $[48,4 \%-58,2 \%]$.

\section{Figura 1 - Classificação dos sujeitos da pesquisa de acordo com 0 nível de alfabetismo caracterizado}

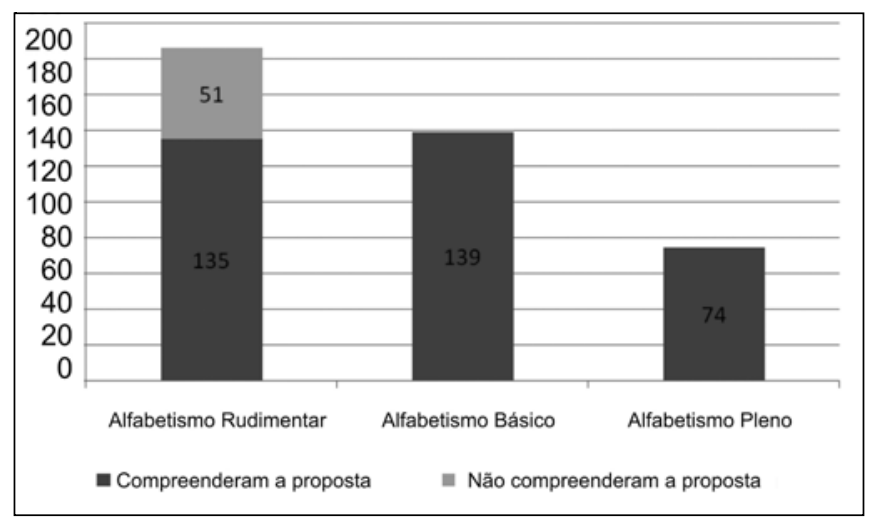

Não há diferença significativa quando realizada a associação entre as variáveis nível de alfabetismo e sexo. ( $p>0,05)$.

Há associação estatística entre as variáveis nível de alfabetismo e nível de escolaridade ( $p<0,05)$.

Quanto ao grupo de analfabetos funcionais, no nível de escolaridade menor ou igual ao Ensino Fundamental eram esperados aproximadamente 56 pessoas, entretanto, a amostra apresentou 82 pessoas nessa classificação. Já nos sujeitos com Ensino Médio, os valores esperados eram maiores do que os achados, 93 (esperado) e 86 (achado). 0 mesmo ocorreu entre as pessoas com Ensino Superior, 37 era o valor esperado, ao passo que foram achados 18 sujeitos.

No grupo dos funcionalmente alfabetizados eram esperados 64 pessoas com o EF, entretanto, apenas 38 pessoas estavam nesse nível de escolarização. No EM, eram esperadas 106 pessoas e foram encontradas 113 , e no ES, o esperado era de 42 pessoas, tendo sido encontradas 62 .

Isto indica que quanto maior a escolaridade, maior probabilidade do sujeito ser funcionalmente alfabetizado. Entretanto, a variável nível de escolaridade, isoladamente, não pode ser 
tomada como um indicador seguro da alfabetização.

Segundo o teste, há associação estatística entre as variáveis nível de alfabetismo e regiões do Brasil. ( $p<0,05$ ).

No grupo de analfabetos funcionais, para os procedentes da região Sudeste do Brasil eram esperados aproximadamente 138 pessoas, entretanto, a amostra apresentou 123. Já na Região Sul, o valor esperado era sete, e foram encontradas nove pessoas. Nas demais regiões do país, esperava-se encontrar 41 pessoas analfabetos funcionais, entretanto, o valor encontrado foi 54 . No grupo dos funcionalmente alfabetizados, a região Sudeste apresentou 173 pessoas, enquanto o esperado era 158, a região Sul do Brasil apresentou cinco e eram esperadas seis pessoas, e as demais regiões do país apresentaram apenas 35 pessoas, o esperado era 48.

O fato do sujeito proceder da região Sudeste era um fator positivo para alfabetização.

Segundo o teste, há associação estatística quando realizada a correlação entre as variáveis nível de alfabetismo e anos de estudo, maior ou menor que oito anos. ( $p<0,05$ ).

No grupo de analfabetos funcionais, as pessoas com menos de oito anos de estudo foram 40, porém o esperado era de apenas 28. Já as pessoas com oito anos ou mais de estudo, 146 foram encontradas, esperava-se que fossem 158. No grupo dos funcionalmente alfabetizados, esperava-se 33 pessoas com menos de oito anos de estudo, entretanto, apenas 21 pessoas foram encontradas. Já as pessoas com oito anos ou mais de estudo foram encontradas 192 e esperava-se 180. Ou seja, quando o sujeito havia frequentado a escola mais de oito anos era maior a probabilidade de ser funcionalmente alfabetizado.

\section{Discussão}

É necessário elaborar o TCLE adequado ao nível de alfabetismo da população usuária de hospitais públicos universitários onde se realizam a maioria das pesquisas clínicas no País.

Os resultados indicam que, provavelmente, a maioria dos usuários do PAMB do HCFMUSP, possíveis sujeitos de pesquisa em ensaios clínicos, não dominam as habilidades requeridas para ler e compreender um TCLE, já que a maioria dos entrevistados não se mostrou totalmente capaz de compreender de maneira clara um texto informativo compatível com o TCLE.

Das 139 pessoas $(34,8 \%)$ caracterizadas como alfabetizadas em nível básico, 109 delas lembraram da alternativa que estava mais explícita no texto, "extinção de espécies animais e vegetais" ao passo que apenas 39 pessoas lembraram apenas da alternativa menos evidente do texto "o aumento do volume de água dos rios". Esta diferença pode estar ligada à ordem e ênfase das informações contidas no texto do instrumento. Em um texto expositivo a utilização de marcadores explícitos são percebidas mais facilmente e reproduzidas pelos sujeitos ${ }^{8}$. Essa estratégia serve para que a memória do leitor seja ativada.

$O$ índice de analfabetos funcionais no PAMB-HCFMUSP $(46,6 \%)$ ficou acima da média nacional (32\%) e o de funcionalmente alfabetizados $(53,4 \%)$ abaixo $(68 \%)^{4}$. Isto indica o rigoroso cuidado que se deve ter ao redigir um TCLE nas pesquisas clínicas feitas no HCFMUSP.

A maioria da amostra deste estudo foi classificada como alfabetizada em nível rudimentar e básico. Os alfabetizados no nível rudimentar são capazes de localizar uma informação explícita em textos curtos e familiares, como em anúncios ou cartas. São capazes de ler e escrever números em contextos específicos como preço, horário, números de telefone e realizar operações simples, como manusear dinheiro para o pagamento de pequenas quantias ou fazer medidas de comprimento usando a fita métrica ${ }^{4,9}$.

Os classificados no nível básico de alfabetização são capazes de ler e compreender textos de média extensão, localizar informações nestes textos, fazendo pequenas inferências leem números na casa dos milhões e possuem noção de proporcionalidade ${ }^{4,9}$.

Os sujeitos classificados como alfabetizados em nível pleno, minoria no estudo, possuem habilidades sem restrições para compreender e interpretar elementos usuais da sociedade letrada podem ler textos mais longos relacionando suas partes comparam e interpretam informações, distinguem fato de opinião, realizam inferências e sínteses ${ }^{4,9}$.

Reforça-se a recomendação da Res. 196/96 item IV.2 - a redação do TCLE deve ser feita pelo pesquisador responsável, considerando as características de compreensão de leitura da população usuária do seu centro.

O TCLE deve ser adaptado às peculiaridades de cada situação, e, especialmente, dos sujeitos. Apesar da dificuldade de sua compreensão por parte dos sujeitos, não há impedimento de que ele ocorra. Providências como a inclusão de ilustrações e a alteração do nível de dificuldade de leitura do texto podem melhorar o nível de compreensão das informações fornecidas pela equipe ${ }^{9}$. Da mesma maneira, realizar a transmissão coletiva de informações - permitiria a utilização de mais tempo, bem como o uso de outros recursos, como meios audiovisuais, habitualmente não utilizados na obtenção do consentimento ${ }^{9}$.

Acredita-se que ao formular um TCLE o pesquisador deve ter cuidado em redigir com linguagem leiga, ou seja, não médica. Os usuários dos hospitais universitários procedem das camadas populares, que usam dialetos populares, dialetos não-padrão, que ainda não possuem expressão escrita. Ao redigir um texto para essas pessoas é preciso fazer uma espécie de tradução, redigindo em dialeto padrão não médico, de maneira mais fácil de ler e compreender, ou seja, em uma linguagem mais próxima possível do dialeto popular.

Para compreender o que está escrito, a pessoa depende da memória. A memória permanente é onde o leitor armazena seus conhecimentos prévios, as informações extra textuais que contribuirão para a construção do significado do texto lido. A memória imediata ou temporária armazena sequências de números ou palavras. A memória de médio termo permite integrar significados provenientes de elementos do texto que está sendo lido ${ }^{8}$. Durante a leitura de um TCLE, os possíveis sujeitos de pesquisa utilizam as três formas de memória, porém destaca-se que a leitura deveria ser capaz de estimular especialmente a utilização da memória de médio termo para que ele pudesse confrontar a proposta com seus desejos, crenças, valores e opções.

Há recomendações para orientar o trabalho do redator que convergem para a produção de textos informativos, em dialeto padrão, e acessíveis a leitores adultos de camadas populares ${ }^{8,11}$. Estes leitores são aqueles que em sua maioria não dominam ou dominam apenas parcialmente o dialeto padrão e cuja experiência em leitura é limitada em quantidade e variedade ${ }^{8}$.

Resumidamente, estas recomendações incluem: ajudar o 
leitor a ativar os conhecimentos que tem sobre o assunto do texto; ajudar o leitor a predizer o texto, imaginar sua estrutura e seus conteúdos; respeitar os limites da memória imediata do leitor; descobrir as palavras que o leitor conhece e utilizá-las; explicar as palavras que o leitor não conhece no próprio texto; descobrir o campo de conhecimentos do mundo do leitor para a partir dele apresentar informações novas; usar a estrutura narrativa sempre que possível; pois é a que o leitor conhece melhor; dirigir-se ao leitor; cooperar com o leitor na sua expectativa quanto ao texto ser coerente, parcimonioso, canônico e coeso ${ }^{8}$.

Estas recomendações parecem úteis e fundamentais para auxiliar na elaboração de um TCLE mais fácil de ler e compreender.

\section{Conclusões}

Com base nos resultados e nas discussões recomendamos à redação do TCLE:

- elaborar textos curtos, de conteúdo simples no qual o sujeito possa localizar, de maneira direta e clara, as informações que precisa para decidir;

- equilibrar, na redação do texto, as necessidades de esclarecer e ser breve, elaborando um texto de extensão suficiente para que o sujeito leia-o integralmente e compreenda os procedimentos da pesquisa;

- utilizar a estrutura narrativa para a explicação dos procedimentos da pesquisa nos quais a participação do sujeito ocorrerá;

- formular o texto em linguagem leiga, usando palavras e termos que sejam familiares aos sujeitos, ou seja, usar termos comuns aos sujeitos e à linguagem médica. Quando existir a necessidade de utilizar termos médicos, estes deverão ser explicados em linguagem leiga, logo após a inclusão do termo médico;

- elaborar o texto de maneira dirigida ao leitor como se fosse um diálogo do pesquisador com o sujeito;

- formular parágrafos dedutivos com a informação temática no início;

- colocar as informações mais importantes para a decisão no início das frases;

- utilizar frases na ordem direta, curtas, afirmativas e com poucas palavras ;

- substituir expressões com duas negativas por uma afirmativa e expressões compostas e palavras derivadas por termos curtos;

- usar voz ativa; evitar a voz passiva e quando for preciso usá-la, explicitar o agente da ação;

- citar o positivo antes do negativo, ou seja, a causa antes do efeito, os benefícios antes dos desconfortos e riscos;

- evitar o uso de adjetivos, advérbios, eufemismos e modismos;

- repetir termos para facilitar a compreensão do texto;

- utilizar escalas para expressar os riscos da pesquisa para o sujeito e não porcentagens;

- utilizar títulos e subtítulos em destaque, assim, o leitor poderá predizer as próximas informações a partir da leitura do título;

- utilizar títulos como marcadores explícitos que poderão ser facilmente lembrados e reproduzidos pelos sujeitos;

- utilizar perguntas como subtítulos no TCLE, pois isto pode funcionar como um facilitador a mais de sua compreensão. Ao utilizar essa estratégia, a informação deve ser apresentada com linguagem idêntica na pergunta e na resposta.

Acreditamos que estas recomendações para adequar a linguagem do TCLE ao índice de analfabetismo funcional dos possíveis sujeitos de pesquisa com fundamento nas orientações para uma redação de texto centrada no leitor podem ser úteis para intervir no risco das pessoas consentirem suas participações em pesquisas sem entender este instrumento essencial no processo de tomada de decisão.

Além de propiciar as recomendações propostas, este estudo contribuiu para reforçar a necessidade da participação de expertos de diversas áreas do conhecimento nos CEP's e reafirmar a bioética como espaço de confluência de diversas áreas do saber. Isto só enriquecerá e qualificará a pesquisa e a assistência em saúde. Na pesquisa clínica, se boa parte das pendências apontadas pelos CEP's ao avaliarem os protocolos decorrem de problemas relativos à redação do TCLE, apostamos que a adoção destas recomendações poderá ajudar a diminuir o tempo de tramitação dos projetos no sistema de avaliação ética.

\section{Conflito de interesse: não há}

\section{SUMMARY}

\section{HOW TO MAKE CONSENT FORMS EASIER TO READ?}

OBJECITIVE. Define the literacy level of Hospital das Clínicas da Faculdade de Medicina da Universidade de São Paulo (HCMFUSP) outpatients, for the purpose of identifying recommendations to adapt writing of the informed consent form to the outpatients literacy level, since these can become the subject of research.

METHODS. Quantitative cross sectional study with 399 subjects. The sample was intentional, selected from different outpatient care units of HCFMUSP. Data collection used an instrument that contained a text with prose compatible for assessment of reading skills needed for comprehension of the consent form. RESULTS. More than $46.6 \%$ of the interviewees were classified as functionally illiterate, of these, $12.7 \%$ were even unable to understand the proposed task in the text they read. Nevertheless, nearly $50 \%$ of the interviewees reported having at least started high school.

CONCLUSIONS. The results and the orientations for the text writing centered on the reader allowed us to make recommendations to render the consent form easier to read. We recommend that the researcher modifies the text to a structural narrative, addressed to the reader, using terms that are familiar., In other words, with terms common to the subjects' and to the medical language. In addition to improving the relationship between the subject and researcher, it is believed that these recommendations may reduce the time taken for the proceeding of research projects, since problems in the wording of consent forms contribute significantly to project delays. [Rev Assoc Med Bras 2010; 56(2): 151-6]

KEY wORDS: Consent Forms. Educational Status. Bioethics. Ethics Committees. Research.

\section{REFERÊNCIAS}

1. Tannous GS. Descentralização e autonomia dos CEPS: a visão da CONEP sobre o fortalecimento do sistema CEP/CONEP. IN: $7^{\circ}$ Fórum dos Comitês de Ética em Pesquisa do Estado de São Paulo; 2009.

2. Lorenzo C. O consentimento livre e esclarecido e a realidade do analfabetismo funcional do Brasil: uma abordagem para a norma e para além da norma. Rev Bioética. 2007;15(2):268-82. 
3. Instituto Paulo Montenegro. $05^{\circ}$ Indicador Nacional de Alfabetismo Funcional; 2005. [citado ago 2009]. Disponível em: http://www.ipm.org.br.

4. Instituto Paulo Montenegro. O Inaf 2007 - Indicador Nacional de Alfabetismo Funcional; 2007. [citado ago 2009]. Disponível em: http://www.ipm.org.br.

5. Hulley SB, Cummning SR, Browner WS, Grady D, Hearst N, Newman TB, et al. Delineando a pesquisa clínica: uma abordagem epidemiológica. São Paulo: Artmed; 2003

6. Bittencourt VC, Araujo DVP, Protas J, Silva CAM, Goldim JR. Processo de consentimento e alfabetismo funcional. In: 27a Semana Científica do Hospital de Clínicas de Porto Alegre, 2007, Porto Alegre. Anais Porto Alegre: Gráfica HCPA; 2007. v. 27.p. 273.

7. Moreira DA. Analfabetismo funcional: introdução ao problema. 2000. [citado ago 2009]. Disponível em: http://www.ipm.org.br.

8. Bocchini MO. Formação de redatores para a produção de textos acessível a leitores pouco proficientes: o caso de mulher e saúde, boletim do SOF na luta pela saúde das mulheres [tese]. São Paulo: Escola de Comunicações e Artes, Universidade de São Paulo, 1994.]

9. Ribeiro VM. Indicadores de alfabetização no Brasil: problemas e perspectivas. 2003. [citado ago 2009]. Disponível em: http://www.ipm.org.br.

10. Miranda VC, Fêde ABS, Lera AT, Thaumaturgo A, Ueda A, Antonagelo DU, et al. Como consentir sem entender?. Rev Assoc Med Bras. 2009.55(3):328-34.

11. Assumpção MEOO, Bocchini MO. Recomendações para escrever bem textos fáceis de ler. $2^{\mathrm{a}}$ ed. Barueri: Manole; 2006

Artigo recebido: 14/10/09 Aceito para publicação: 20/01/10 